\title{
BLOOD SCHIZONTOCIDAL ACTIVITY OF METHYLENE BLUE IN COMBINATION WITH ANTIMALARIALS AGAINST PlasmodIUM FalCIPARUM
}

\author{
GARAVITO G.*****, BERTANI S.******, RINCON J.*, MAUREL S.****, MONJE M.C.***, LANDAU I.**, \\ VALENTIN A.*** \& DEHARO E.****
}

\section{Summary:}

Methylene blue $(\mathrm{MB})$ is the oldest synthetic antimalarial. It is not used anymore as antimalarial but should be reconsidered. For this purpose we have measured its impact on both chloroquine sensitive and resistant Plasmodium strains. We showed that around $5 \mathrm{nM}$ of $\mathrm{MB}$ were able to inhibit $50 \%$ of the parasite growth in vitro and that late rings and early trophozoites were the most sensitive stages; while early rings, late trophozoites and schizonts were less sensitive. Drug interaction study following fractional inhibitory concentrations $(\mathrm{FIC})$ method showed antagonism with amodiaquine, atovaquone, doxycycline, pyrimethamine; additivity with artemether, chloroquine, mefloquine, primaquine and synergy with quinine. These results confirmed the interest of $M B$ that could be integrated in a new low cost antimalarial combination therapy.

KEY WORDS : antimalarials, Plasmodium, methylene blue, drug interactions.

\section{INTRODUCTION}

$\mathrm{M}$ alaria remains one of the most important parasitosis in tropical developing countries, killing 1-3 million people (mostly children) in subSaharan Africa, and causing disease in 300-500 million people a year. Despite international commitment to control and research, the reality for many patients is much as it was twenty years ago: they still die because being unable to access treatment for economic reasons. Moreover available drugs are not efficient due to parasite resistance (Olliaro, 2005). In this context, new, safe, affordable and efficient drugs against resistant strains of Plasmodium are needed. In addition to be effective against drug resistant malaria, an ideal new can-

\footnotetext{
* Departamento de Farmacia, Facultad de Ciencias, Universitad Nacional de Colombia, Carrera 30 45-03 Bogotá D.C., Colombia. ** Laboratoire de Parasitologie Comparée et Modèles Expérimentaux, Muséum National d'Histoire Naturelle, USM 0307, 61, rue Buffon, 75231 Paris Cedex 05, France.

**** Pharmacochimie des Substances Naturelles et Pharmacophores Redox, Faculté des Sciences Pharmaceutiques, UMR-152 IRD-Université de Toulouse 3, 31062 Toulouse Cedex 9, France. Correspondence: Eric Deharo.

Fax: +33 (0)5 62259802 - E-mail: ericdeharo@yahoo.fr
}

Résumé : ACTIVITÉ DU BLEU DE MÉTHYLÈNE EN COMBINAISON AVEC Des antipaludiques Contre les Stades SANGUins De Plasmodium FALCIPARUM

Le bleu de méthylène (BM) est l'antipaludique de synthèse le plus ancien. Il n'est désormais plus employé comme antipaludique, mais son usage devrait être reconsidéré. Nous avons mesuré son effet sur des souches de Plasmodium chloroquino-sensibles et chloroquino-résistantes. Nous avons montré que $5 \mathrm{nM}$ de BM inhibent $50 \%$ du développement parasitaire in vitro et que les stades anneaux mûrs et trophozoites jeunes sont les stades les plus sensibles tandis que les trophozoites âgées, les schizontes et les anneaux jeunes sont les moins sensibles. L'étude de l'interaction de drogues selon la méthode des concentrations inhibitrices fractionnelles ou FIC montre que l'association avec le MB est: antagoniste avec l'amodiaquine, l'atovaquone, la doxycycline et la pyriméthamine, additive avec l'artéméther, la chloroquine, la méfloquine et la primaquine et synergique avec la quinine. Ces résultats confirment l'intérêt du BM qui pourrait être intégré dans une nouvelle thérapie antipaludique de combinaison à prix réduit.

MOTS CLÉS : antipaludiques, Plasmodium, bleu de méthylène, interaction de drogues.

didate must be effective within a three-day regimen, safe in small children ( $<6$ months) and pregnant women, easy to package, cheap and have a low propensity to generate resistance (Baird, 2005; Pink et al., 2005).

Adapted to oral administration, MB gathers all these features except one: it is not new anymore. In 1891, Ehrlich \& Guttmann (1891) used MB to treat two patients infected by Plasmodium; for the first time a synthetic drug was shown to be active against malaria. Later, MB along with quinine, served as structural starting points for the development of 8-aminoquinoline (pamaquine) and 9-aminoacridine (mepacrine, quinacrine) in 1925 and 1930, respectively (Schulemann, 1932). Since that time, few works on the antimalarial properties of $\mathrm{MB}$ have been reported because it was thought to enhance hemolysis in case of glucose-6phosphate-deshydrogenase (G6PD) deficiency (Schirmer et al., 2003) and could stain the tissues of MB-treated people (Wainwright \& Amaral, 2005). Nevertheless, Mandi et al. (2005) and Meissner et al. (2005) found recently that G6PD deficiency did not compromise the use of MB for malaria treatment, even in class III G6PD deficient young children. Recently, Akoachere et al. (2005) studied the interaction between MB and clas- 
sical antimalarial drugs, and found $\mathrm{MB}$ to be antagonistic with amodiaquine and chloroquine. This sounded strange to us, as $\mathrm{MB}$ is an exceptionally weak base (pKa 0-1) (Keene et al., 1965; Pottier et al., 1975) accumulating inside malaria-infected red blood cell in which it is reduced and probably concentrated in the food vacuole where it inhibits the formation of hemozoin (Atamna et al., 1996), just as 4-aminoquinolines do. Moreover, MB inhibits parasite glutathione reductase thus jeopardizes glutathione functionality (Färber et al., 1998). Instead of antagonise, this phenomenon should enhance chloroquine activity, which is closely related to glutathione levels (Meierjohann et al., 2002). We thus re-examined herein the activity of $\mathrm{MB}$ on African and South-American P. falciparum strains, determined the most sensitive parasitic stage and studied the association of MB with classical antimalarial drugs, as the spread of multidrug-resistant Plasmodium strains favours the use of combinations to protect the individual compounds from emergence of resistance [WHO-TDR, 2006].

\section{MATERIALS AND METHODS}

\section{Chemicals}

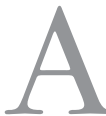
ll chemicals were from Sigma-Aldrich (L'Isle d'Abeau Chesnes, France) except artemether (ART) from Cambrex (Verviers, Belgium), atovaquone (ATO) was a gift from GlaxoSmithKline (Marlyle-Roi, France) and mefloquine (MEF) from HoffmannLa Roche (Basel, Switzerland).

Amodiaquine (AMO), ART, ATO, chloroquine (CQ), doxycycline (DOX), MB, primaquine (PRIM), pyrimethamine (PYR), quinine (Q) and MEF were dissolved in appropriate solvents and then with RPMI 1640 medium (Cambrex). All final concentrations of solvent were $<0.01 \%$, as recommended by Ye et al. (1983).

\section{PLASMODIUM FALCIPARUM IN VITRO}

Four uncloned strains of P. falciparum were used: F32Tanzania, HB3-Honduras, FcM29-Cameroon and FcB1Colombia. Parasites were cultured according to Trager and Jensen (1976) on human type O+ erythrocytes in RPMI 1640 medium supplemented with 25 mM HEPES buffer, $10 \% \mathrm{AB}$ human serum (3-5\% hematocrit), $2 \mathrm{mg}$ of sodium bicarbonate $/ \mathrm{ml}, 0.5 \mu \mathrm{g}$ of gentamicin $/ \mathrm{ml}$ and incubated at $37^{\circ} \mathrm{C}$ in a reduced oxygen environment (e.g. a custom mixture of $5 \% \mathrm{CO}_{2}, 5 \% \mathrm{O}_{2}$ and $90 \% \mathrm{~N}_{2}$ ).

\section{BIOASSAYS}

The in vitro drug study was adapted from the microdilution technique of Desjardins et al. (1979). Each drug was tested for $48 \mathrm{~h}$ in triplicate in 96-well plates (TPP,
Switzerland) with culture at ring stage (synchronization by $5 \%$ D-sorbitol lysis; Sigma-Aldrich) and 0.5-2\% parasitemia (hematocrit: $1.5 \%$ ). Parasite growth was estimated by $\left[{ }^{3} \mathrm{H}\right]$-hypoxanthine (PerkinElmer, Courtaboeuf, France) incorporation $(1.44 \mu \mathrm{Ci} / \mathrm{ml})$; plates were frozen-defrosted and each well was harvested onto a glass fibber filter (PerkinElmer). Incorporated $\left[{ }^{3} \mathrm{H}\right]-$ hypoxanthine was then determined with a $\beta$-counter (1450-Microbeta Trilux, Wallac-PerkinElmer); controls were performed to assess the background (negative control) and the parasite growth (positive control). The $\mathrm{IC}_{50}$ of the different strains of P. falciparum were determined with a linear least square regression analysis. Stage specificity tests were performed on FcB1 strain. Drugs were tested in triplicate against a culture synchronized for a $6 \mathrm{~h}$ period by treatment with Plasmion (Laboratoire Fresenius Kabi, France) and consecutive $5 \%$ D-sorbitol lysis (Lelièvre et al., 2005). After each exposition, treated wells were washed twice with RPMI and cells returned to normal culture conditions until time zero plus $48 \mathrm{~h}$ (Valentin et al., 1997). [ $\left.{ }^{3} \mathrm{H}\right]$-hypoxanthine $(0.5 \mu \mathrm{Ci} /$ well $)$ was then added and plates were incubated for another $36 \mathrm{~h}$. Results were expressed as percentage of inhibition versus controls without drug. Combination experiments were performed with FcM29 strain. Drugs were combined in 96 wells microtitration test plates at various fractions of their respective $\mathrm{IC}_{50}$. Results were expressed as the mean sums of the fractional inhibitory concentrations (FIC), defined as ( $\mathrm{IC}_{50}$ of drug $\mathrm{A}$ in mixture $/ \mathrm{IC}_{50}$ of drug $\mathrm{A}$ alone $)+\left(\mathrm{IC}_{50}\right.$ of drug $\mathrm{B}$ in mixture/ $\mathrm{IC}_{50}$ of drug $\mathrm{B}$ alone) for each fixed concentration (Berenbaum, 1978; Canfield et al., 1995). Three types of drug interaction were defined as follows: additivity, sum of FIC $=1$; synergism, sum of FIC $<1$; and antagonism, sum of FIC $>1$ (Ringwald $e t$ al., 1999; Ankoachere et al 2005). We followed this classification to get comparable results with Ankoachere study, although Odds (2003) suggested much more restrictive definitions: synergism (FIC $\leq 0.5$ ), no interaction (FIC $>0.5-4$ ) and antagonism (FIC > 4) (Odds, 2003).

\section{RESULTS}

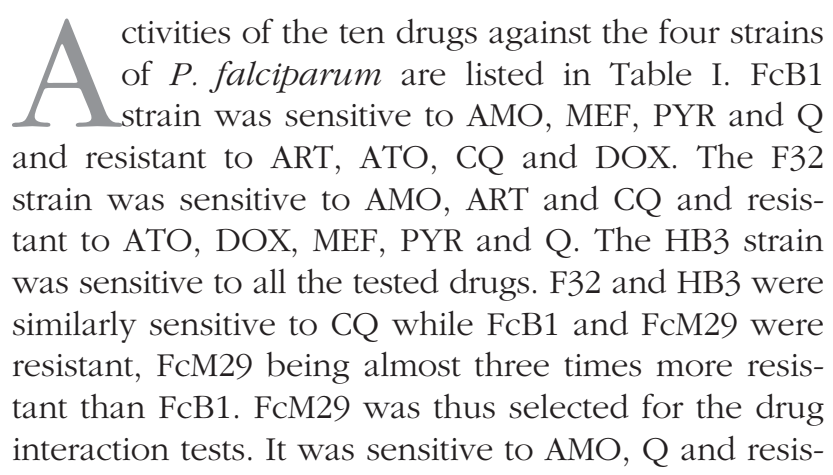




\begin{tabular}{|c|c|c|c|c|c|c|c|}
\hline \multirow[b]{2}{*}{ Compounds } & \multicolumn{4}{|c|}{$\mathrm{IC}_{50}(\mathrm{nM})$} & \multirow{2}{*}{$\begin{array}{l}\text { Resistance } \\
\text { threshold }^{\mathrm{a}}\end{array}$} & \multirow{2}{*}{$\begin{array}{l}\text { FIC Mean }^{\text {b }} \\
\text { FcM29 }\end{array}$} & \multirow[b]{2}{*}{ Interactions } \\
\hline & F32 & HB3 & FcB1 & FcM29 & & & \\
\hline Amodiaquine & 19 & 23 & 22 & 33 & $>60$ & $1.28 \pm 0.11$ & Antagonism \\
\hline Artemether & 0,4 & 10 & 14 & 16 & $>12$ & $0.95 \pm 0.05$ & Additivity \\
\hline Atovaquone & 20 & 0,1 & 22 & 188 & $>7$ & $1.24 \pm 0.17$ & Antagonism \\
\hline Chloroquine & 70 & 36 & 186 & 600 & $>100$ & $1.03 \pm 0.08$ & Additivity \\
\hline Doxycycline & 26,185 & 4,446 & 12,540 & 22,632 & $>9,600$ & $1.44 \pm 0.28$ & Antagonism \\
\hline Mefloquine & 401 & 31 & 16 & 106 & $>30$ & $0.97 \pm 0.12$ & Additivity \\
\hline Methylene blue & 5 & 4 & 8 & 5 & ND & - & - \\
\hline Primaquine & 4,627 & ND & 432 & 13,20 & ND & $0.93 \pm 0.08$ & Additivity \\
\hline Pyrimethamine & 6,882 & ND & 97 & 21,774 & $>2,000$ & $1.15 \pm 0.10$ & Antagonism \\
\hline Quinine & 835 & 208 & 423 & 331 & $>500$ & $0.74 \pm 0.11$ & Synergy \\
\hline
\end{tabular}

Interactions : additivity, sum of FIC $=1$; synergism, sum of FIC $<1$; and antagonism, sum of FIC $>1$ (according to Ankoachere et al., 2005).

${ }^{a}$ Information provided by the Centre national de référence sur la chimiorésistance du paludisme, Institut Pasteur de Guyane; ${ }^{\mathrm{b}}$ FIC mean $=$ mean sum of fractional inhibitory concentrations \pm SD (obtained from 5 to 20 determinations); ND: not determined.

Table I. - In vitro activity of MB blue and classical antimalarials (alone or in combination) against different strains of $P$. falciparum.
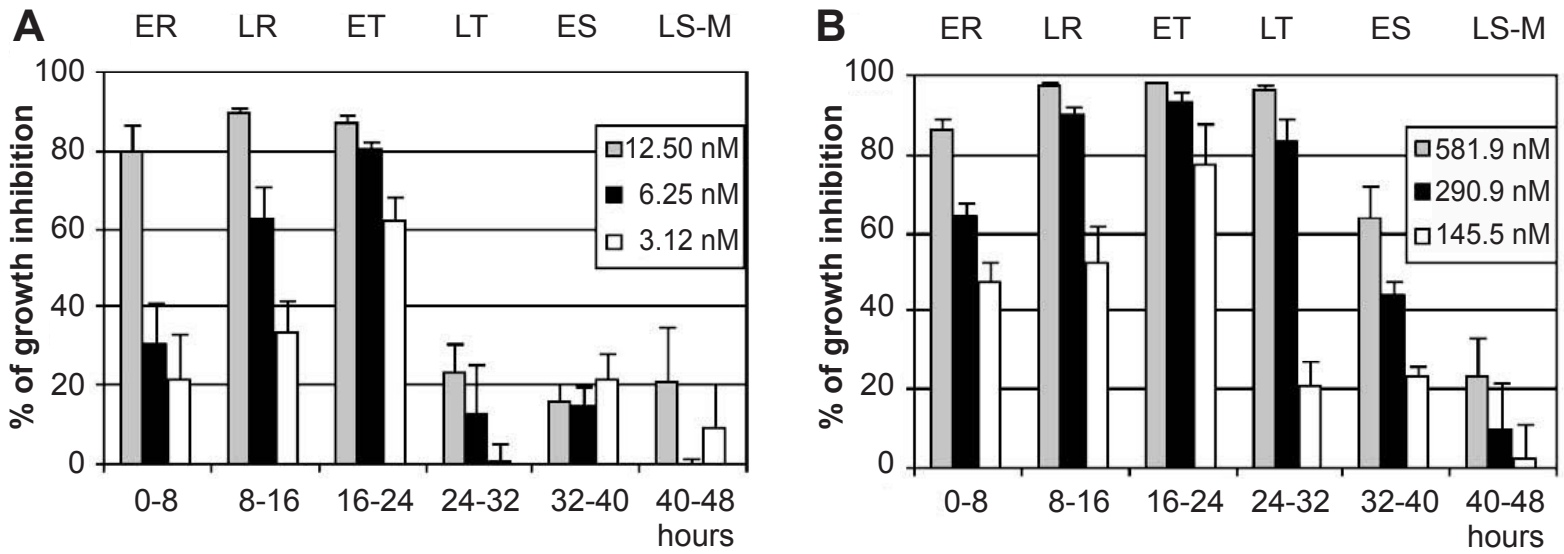

$\mathrm{ER}=$ early rings; $\mathrm{LR}=$ late rings; $\mathrm{ET}=$ early trophozoites; $\mathrm{LT}=$ late trophozoites; $\mathrm{ES}=$ early schizonts; $\mathrm{LS}=$ late schizonts; $\mathrm{M}=$ merozoites; Average +/- SD.

Fig. 1. - Sensitivity of the different stages of P. falciparum FcB1 strain to increasing doses of methylene blue and quinine: (A) methylene blue; (B) quinine.

tant to the other drugs (except MB). MB was highly active against the four strains of $P$. falciparum, being the most active of all tested drugs. When tested on highly synchronized parasites, it appeared that late rings and early trophozoites were the most sensitive stages to MB (Fig. 1). This was similar for Q who additionally displayed good activity on late trophozoites (Fig. 1). Early rings were moderatly sensitive, whereas early and late schizonts showed the lowest susceptibility for the two drugs. Late trophozoites were sensitive to $\mathrm{Q}$ but not to MB.

Results of the combination studies following the criteria defined by Ankoachere et al. (2005) indicated that interactions with $\mathrm{MB}$ ranged from antagonism to synergism (see Table I and Fig. 2): antagonism with AMO, ATO, DOX and PYR; additivity with ART, CQ, MEF and PRIM; and synergy with quinine. According to the scale defined by Odds (2003), there is no interaction between $\mathrm{MB}$ and all tested drugs.

\section{DISCUSSION AND CONCLUSION}

M ethylene blue has already been shown to be active alone in vitro against laboratory-adapted strains from various geographic regions, with $\mathrm{IC}_{50}$ ranging from 3 to $11 \mathrm{nM}$ (Atamna et al., 1996; Vennerstrom et al., 1995). Our results further demonstrated the in vitro activity of $\mathrm{MB}$ against $\mathrm{F} 32$ and $\mathrm{HB} 3$ chloroquine-sensitive strains, and FCM29 and FcB1 chloroquine-resistant strains of $P$. falciparum with the same range of activity $(\sim 5 \mathrm{nM})$. Akoachere et al. (2005) showed that MB was active against K1-South East Asia and Dd2-Indochina chloroquine-resistant strains at around $7 \mathrm{nM}$. That means that $\mathrm{MB}$ is strongly active against strains from all over the world including chloroquine-resistant strains. Subjecting a synchronized culture to pulses of MB every $8 \mathrm{~h}$ for $48 \mathrm{~h}$ (Fig. 1) we showed that MB inhibited around $60 \%$ of the parasite growth between the $8^{\text {th }}$ to the $24^{\text {th }} \mathrm{h}$ of the parasite cycle 
(at $6.25 \mathrm{nM}$ ) when the production of plasmodial RNA and protein are maximal (Arnot \& Gull, 1998). That is consistent with the fact that the antimalarial activity of MB depends on the Plasmodium antioxydant defences, which are fully functional at the late ring-early trophozoite stages when intensive digestion of haemoglobin occurs. This is also correlated with the peak of expression of plasmodial glutathione reductase (PF140192), which is targeted by MB (Färber et al., 1998), starting 8 hours post invasion and reaching its maximum at the $24^{\text {th }}$ hour of the intraerythrocytic cycle (PlasmoDB, 2005). With the emergence and spread of drug resistance in malaria endemic regions, combination therapy repre- sents an effective approach in curbing the development of resistance of the parasite to the commercially available compounds (Gupta et al., 2002). Additionally it may reduce toxicity and shorter treatment regimens (Pink et al., 2005). Akoachere et al. (2005) found MB to be antagonistic with AMO, CQ, PRIM and PYR; additive with MEF and Q; synergistic with ART, artemisinin and artesunate, against P. falciparum K1 strain in culture. Antagonism with AMO and CQ is surprising as MB (like 4-aminoquinolines) concentrated in Plasmodium food vacuole where it inhibits the formation of hemozoin (Atamna et al., 1996). It is also known to inhibit parasite glutathione reductase (Färber et al.,
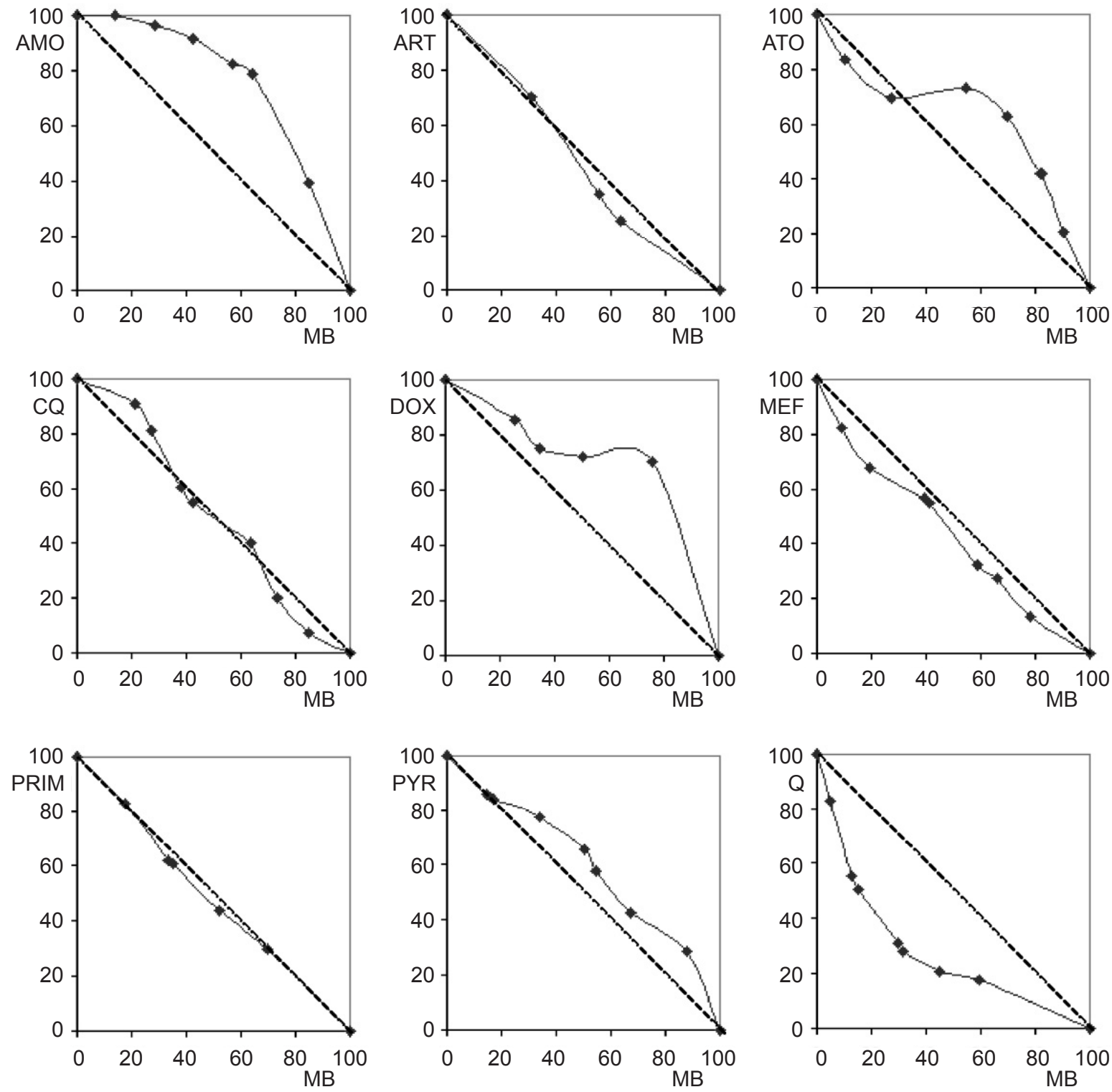

The straight line in each panel represents additivity. Points located below this line indicate synergism, data points above the line indicate antagonism.

$\mathrm{AMO}=$ amodiaquine; $\mathrm{ART}=$ artemether $\mathrm{ATO}=$ atovaquone; $\mathrm{CQ}=$ chloroquine; $\mathrm{DOX}=$ doxycycline $; \mathrm{MEF}=$ mefloquine; $\mathrm{MB}=$ methylene blue; PRIM = primaquine; $\mathrm{PYR}=$ pyrimethamine $; \mathrm{Q}=$ quinine .

Fig. 2. - Isobolograms of drug interactions between MB and other antimalarial drugs. 
1998) enhancing chloroquine activity (Meierjohann et al., 2002). We thus decided to study the interaction between $\mathrm{MB}$ and known antimalarials with a slightly different model from that of Akoachere et al. (2005). We started with higher (1-2\%) parasitemia and initiated radio labelling at time zero plus $32 \mathrm{~h}$ for $16 \mathrm{~h}$. We ended the experiment after $48 \mathrm{~h}$ incubation. We found antagonism with $\mathrm{MB}+\mathrm{AMO}, \mathrm{ATO}, \mathrm{DOX}$ and PYR while in the Akoachere's study AMO, CQ, PRIM and PYR were antagonist. Although AMO belongs to the same chemical class of compounds as CQ, the 4-aminoquinolines, the association of $\mathrm{MB}$ and this drug was antagonist in both studies, this must be due to the fact that the antimalarial activity of AMO is mainly exerted through its metabolite, desethylamodiaquine (Mariga et al., 2005). DOX and PYR are very cheap, unfortunately these products were antagonist with $\mathrm{MB}$ against $P$. falciparum FcM29 strain (DOX was not tested in Akoachere's study and PYR was also found antagonist). In our hands, the association of $\mathrm{MB}$ with $\mathrm{Q}$ was synergic (additive in Akoachere's study). Q present similarities with $\mathrm{MB}$ : we showed that the activity of the two drugs was directed against initial stages of the blood cycle (Q being also slightly active against late trophozoites). As MB, Q is a weak membrane-soluble base, accumulating in the acidic digestive vacuole contents where it undergoes protonation. Unfortunately Q use is limited by its long therapy duration, entailing poor adherence with high risk of failure, and its potential toxicity in people with G6PD deficiency (Baird, 2005). Additive interactions were also observed between $\mathrm{MB}$ and ART, CQ, MEF and PRIM. ART is a drug of choice and was found to be synergic in Akoachere's study (Akoachere et al., 2005). Despite a prohibitive price making their deployment difficult, artemisinin-based combination therapies (ACTs) are the best antimalarial treatments available nowadays and are recommended by WHO since 2001 (Mutabingwa, 2005). MEF was additive in both studies but it is not an optimal candidate because persistence of subinhibitory concentrations for long periods (elimination $\mathrm{t}_{1 / 2}$, 2 weeks) (Karbwang et al., 1988; Mansor et al., 1989). CQ remains one of the cheapest antimalarial easily accessible in developing countries. Rengelshausen et al. (2004) showed that oral co-administration of MB and CQ did not show major pharmacokinetic interactions confirming the feasibility of this combination. Nevertheless, in a trial conducted in Burkina Faso, where high resistance of Plasmodium to CQ was reported, Meissner et al. (2006) found that the CQ-MB combination was not sufficently effective in the treatment of uncomplicated malaria in young children. This observation was correlated with antagonism reported by Akoachere et al. (2005), between CQ and MB.

In conclusion, according to Akoachere et al. (2005) criteria: additivity with MEF and antagonism with AMO were supported in both studies. Q was synergic in our hands and additive in their study. ART was synergic in Akoachere's study and additive for us. On the contrary we found additivity with CQ and PRIM while antagonism was claimed by Akoachere et al. (2005). We also showed antagonism with DOX and ATO, not tested elsewhere. These discrepancies suggest that in vivo studies with animal models should be conducted to determine adequate associations.

\section{ACKNOWLEDGEMENTS}

$\checkmark$ iovanny Garavito was awarded a PhD fellowship supported by the Programme Alban, the European Union Programme of High Level Scholarships for Latin America scholarship No. E04D039384CO. Stéphane Bertani was awarded a PhD fellowship from the Pierre \& Marie Curie University, Paris 6, and the Ministère délégué à la Recherche, France.

Ginsburg H. of the Hebrew University of Jerusalem and José Perea S. of the National University of Colombia are appreciated for illuminating discussions. We gratefully acknowledge receipt of some antimalarials from Esterre P. and Legrand E. from the Institut Pasteur de Guyane, France. We thank Pelissou E. for helpful technical assistance.

\section{REFERENCES}

Akoachere M., Buchholz K., Fischer E., Burhenne J., Haefeli W.E., SChirmer R.H. \& BeCKer K. In vitro assessment of methylene blue on chloroquine-sensitive and -resistant Plasmodium falciparum strains reveals synergistic action with artemisinins. Antimicrobial Agents and Chemotherapy, 2005, 49 (11), 4592-4597.

Arnot D.E. \& Gull K. The Plasmodium cell-cycle: facts and questions. Annals of Tropical Medicine and Parasitology, 1998, 92, 361-365.

atamna H., Krugliak M., Shalmiev G., Deharo E., Pescarmona G. \& Ginsburg H. Mode of antimalarial effect of methylene blue and some of its analogues on Plasmodium falciparum in culture and their inhibition of $P$. vinckei petteri and P. yoelii nigeriensis in vivo. Biochemical Pharmacology, 1996, 51, 693-700.

BAIRD J.K. Effectiveness of antimalarial drugs. The New England Journal of Medicine, 2005, 352 (15), 1565-1577.

Berenbaum M.C. A method for testing for synergy with any number of agents. The Journal of Infectious Diseases, 1978, 137 (2), 122-130.

Canfield C.J., Pudney M. \& Gutteridge W.E. Interactions of atovaquone with other antimalarial drugs against Plasmodium falciparum in vitro. Experimental Parasitology, 1995, 80, 373-381.

Desjardins R.E., Canfield C.J., Haynes J.D. \& Chulay J.D. Quantitative assessment of antimalarial activity in vitro by a semiautomated microdilution technique. Antimicrobial Agents and Chemotherapy, 1979, 16 (6), 710-718. 
Ehrlich P. \& Guttmann P. Ueber die Wirkung des Methylenblau bei Malaria. Berliner klinische Wochenschrift, 1891, 28, 953-956.

Färber P.M., Arscott L.D., Jr. Williams C.H., Becker K. \& SCHIRMER R.H. Recombinant Plasmodium falciparum glutathione reductase is inhibited by the antimalarial dye methylene blue. FEBS Letters, 1998, 422, 311-314.

Gupta S., Thapar M.M., Mariga S.T., Wernsdorfer W.H. \& BJÖRKMAN A. Plasmodium falciparum: in vitro interactions of artemisinin with amodiaquine, pyronaridine, and chloroquine. Experimental Parasitology, 2002, 100, 28-35.

Karbwang J., Back D.J., Bunnag D. \& Breckenridge A.M. A comparison of the pharmacokinetics of mefloquine in healthy Thai volunteers and in Thai patients with falciparum malaria. European Journal of Clinical Pharmacology, 1988, 35 (6), 677-680.

KeEne J.P., Land E.J. \& Swallow A.J. A pulse radiolysis study of methylene blue, in: Pulse Radiolysis. Ebert M., Keene J.P., Swallow A.J., Baxendale J.H. (Eds), London, Academic Press, 1965, 227-244.

Lelièvre J., Berry A. \& BenoIT-Vical F. An alternative method for Plasmodium culture synchronization. Experimental Parasitology, 2005, 109, 195-197.

Mandi G., Witte S., Meissner P., Coulibaly B., Mansmann U., Rengelshausen J., Schiek W., Jahn A., SAnOn M., Wüst K., Walter-SaCk I., Mikus G., Burhenne J., Riedel K.D., Schirmer H., KOUYATÉ B. \& MüLLER O. Safety of the combination of chloroquine and methylene blue in healthy adult men with G6PD deficiency from rural Burkina Faso. Tropical Medicine and International Health, 2005, 10, 32-38.

Mansor S.M., Navaratnam V., Mohamad M., Hussein S., Kumar A., JAMALUdin A. \& WeRnSDORFER W.H. Single dose kinetic study of the triple combination mefloquine/sulphadoxine/pyrimethamine (Fasimef) in healthy male volunteers. British Journal of Clinical Pharmacology, 1989, 27 (3), 381-386.

Mariga S.T., Gil J.P., Wernsdorfer W.H. \& BjöRkman A. Pharmacodynamic interactions of amodiaquine and its major metabolite desethylamodiaquine with artemisinin, quinine and atovaquone in Plasmodium falciparum in vitro. Acta Tropica, 2005, 93, 221-231.

Meierjohann S., Walter R.D. \& MülLer S. Regulation of intracellular glutathione levels in erythrocytes infected with chloroquine-sensitive and chloroquine-resistant Plasmodium falciparum. Biochemical Journal, 2002, 368 (Pt 3), 761-768.

Meissner P.E., Mandi G., Coulibaly B., Witte S., Tapsoba T., Mansmann U., Rengelshausen J., Schiek W., Jahn A., WalterSack I., Mikus G., Burhenne J., Riedel K.D., Schirmer R.H., KOUYATÉ B. \& MÜlLER O. Methylene blue for malaria in Africa: results from a dosefinding study in combination with chloroquine. Malaria Journal, 2006, 5, 84

Meissner P.E., Mandi G., Witte S., Coulibaly B., Mansmann U., Rengelshausen J., Schiek W., Jahn A., Sanon M., Tapsoba T., Walter-Sack I., Mikus G., Burhenne J., Riedel K.D., SchirMer H., Kouyaté B. \& Mueller O. Safety of the methylene blue plus chloroquine combination in the treatment of uncomplicated falciparum malaria in young children of Burkina Faso. Malaria Journal, 2005, 4, 45.

Mutabingwa T.K. Artemisinin-based combination therapies (ACTs): best hope for malaria treatment but inaccessible to the needy! Acta Tropica, 2005, 95, 305-315.
ODDS F.C. Synergy, antagonism, and what the chequerboard puts between them. Journal of Antimicrobial Chemotherapy, 2003, 52, 1.

Olliaro P. Drug resistance hampers our capacity to roll back malaria. Clinical Infectious Diseases, 2005, 4, 247-257.

Pink R., Hudson A., Mouries M.A. \& Bendig M. Opportunities and challenges in antiparasitic drug discovery. Nature, 2005, 4, 727-740.

PlasmoDB, The Plasmodium Genome Resource. November $17^{\text {th }} 2005$ revision date. Expression of Plasmodial glutathione reductase. http://www.plasmodb.org/

Pottier R., Bonneau R. \& Joussot-Dubien J. pH-dependence of singlet oxygen production in aqueous solutions using toluidine blue as a photosensitizer. Photochemical and Photobiological Sciences, 1975, 22, 59-61.

Rengelshausen J., Burhenne J., Frohlich M., Tayrouz Y., Singh S.K., Riedel K.D., Müller O., Hoppe-Tichy T., Haefeli W.E., Mikus G. \& WaLter-SACK I. Pharmacokinetic interaction of chloroquine and methylene blue combination against malaria. European Journal of Clinical Pharmacology, 2004, 60, 10, 709-15.

Ringwald P., Eboumbou E.C.M., Bickit J. \& BASCO L.K. In vitro activities of pyronaridine, alone and in combination with other antimalarial drugs, against Plasmodium falciparum. Antimicrobial Agents and Chemotherapy, 1999, 43 (6), 1525-1527.

Schirmer R.H., Coulibaly B., Stich A., Scheiwein M., Merkle H., Eubel J., Becker K., Becher H., Müller O., Zich T., SchieK W. \& Kouyaté B. Methylene blue as an antimalarial agent. Redox Report, 2003, 8 (5), 272-275.

SChulemann W. Synthetic antimalarial preparations. Proceeding of the Royal Society of Medicine, 1932, 25, 897-905.

Trager W. \& Jensen J.B. Human malaria in continuous culture. Science, 1976, 193, 673-675.

Valentin A., Benoit-Vical F., Moulis C., Stanislas E., Mallié M., FouRASTE I. \& BASTIDE J.M. In vitro antimalarial activity of penduline, a bisbenzylisoquinoline from Isopyrum thalictroides. Antimicrobial Agents and Chemotherapy, 1997, 41 (10), 2305-2307.

Vennerstrom J.L., Makler M.T., Angerhofer C.K. \& Williams J.A. Antimalarial dyes revisited: xanthenes, azines, oxazines, and thiazines. Antimicrobial Agents and Chemotherapy, 1995, 39 (12), 2671-2677.

WAINWRight M. \& AMARAL L. Review: the phenothiazinium chromophore and the evolution of antimalarial drugs. Tropical Medicine and International Health, 2005, 10 (6), 501-511.

WHO-TDR The World Health Organization, Special Programme for Research and Training in Tropical Diseases. April 26th 2006 revision date. Malaria. http://www.who.int/ $\mathrm{tdr} /$ diseases/malaria/default.html

Ye Z.G., Li Z.L., Li G.Q., Fu X.Q., Liu H.P. \& GAO M.X. Effects of Qinghaosu and chloroquine on the ultrastructure of the erythrocytic stage of $P$. falciparum in continuous cultivation in vitro. Journal of Traditional China Medicine, 1983, 3 (2), 95-102.

Reçu le 13 septembre 2006 Accepté le 21 décembre 2006 